\title{
OBSERVATIONS ON HERRING SPAWNING AND LARVAL DISTRIBUTION IN THE FIRTH OF CLYDE IN 1958
}

\author{
By B. B. Parrish, A. Saville, R. E. Craig, \\ I. G. BAXTer AND R. PRIESTLey \\ The Marine Laboratory, Aberdeen \\ (With Plate I and Text-fig. I)
}

Apart from the extensive egg surveys carried out by Norwegian workers (Runnstrom, I94I) most of the investigations on the spawning of the Atlantic Herring have depended on studies of the distribution of the spawning fish, on captures of newly hatched larvae, and on records of the occurrence of herring eggs in the stomachs of predatory fish species (principally haddock). With the exception of recent observations by Bolster and Bridger (1957), attempts to sample egg concentrations quantitatively in the North Sea and neighbouring areas have usually proved abortive. In consequence little is known of the distribution and density of eggs on the spawning grounds, their percentage fertilization, mortality during the egg stage, hatching rate, and the relationship between the distribution of eggs and the nature of the sea-bed.

To study these items, and also the subsequent production, dispersal, and mortality of larvae, and the relationship of these to subsequent year-class strength, it was decided to concentrate effort on the spring spawning in the Firth of Clyde (see Fig. I). This area had been studied much earlier by Cossor Ewart (1884), and it was considered very suitable for intensive study for the following reasons: (i) spawning occurs in a relatively small, well defined, area of shallow depth (13-24 m); (ii) the spawning season is short, extending over a period of about one month; (iii) the main spawning ground is the scene of a small commercial fishery from which detailed information on the distribution and composition of the spawning shoals can be readily obtained; (iv) the dispersal of the larvae can be followed more closely than in the much more extensive regions of the northern North Sea; (v) the region is one in which accurate fixing of position by Decca and land bearings is possible.

The general features of the biology of the herring in the Clyde have been described by Marshall, Nicholls and Orr (1937, I939) and Wood (I951, I958, 1959). Spawning takes place in late February and March in two localities in the outer reaches of the firth, a major one on Ballantrae Bank off the Ayrshire coast of the Scottish mainland, and a smaller one off the south-west corner of the island of Arran. These are shown in Fig. I. Hatching occurs throughout 
March and early April, followed by the dispersal of the larvae from the vicinity of the spawning grounds. The main nursery areas for young herring are located in the upper reaches of the firth where they remain until the onset of first maturity in their third or fourth years of life. After spawning the adults move out of the firth. Only a small proportion of these adults return to the Clyde spawning grounds in subsequent years.

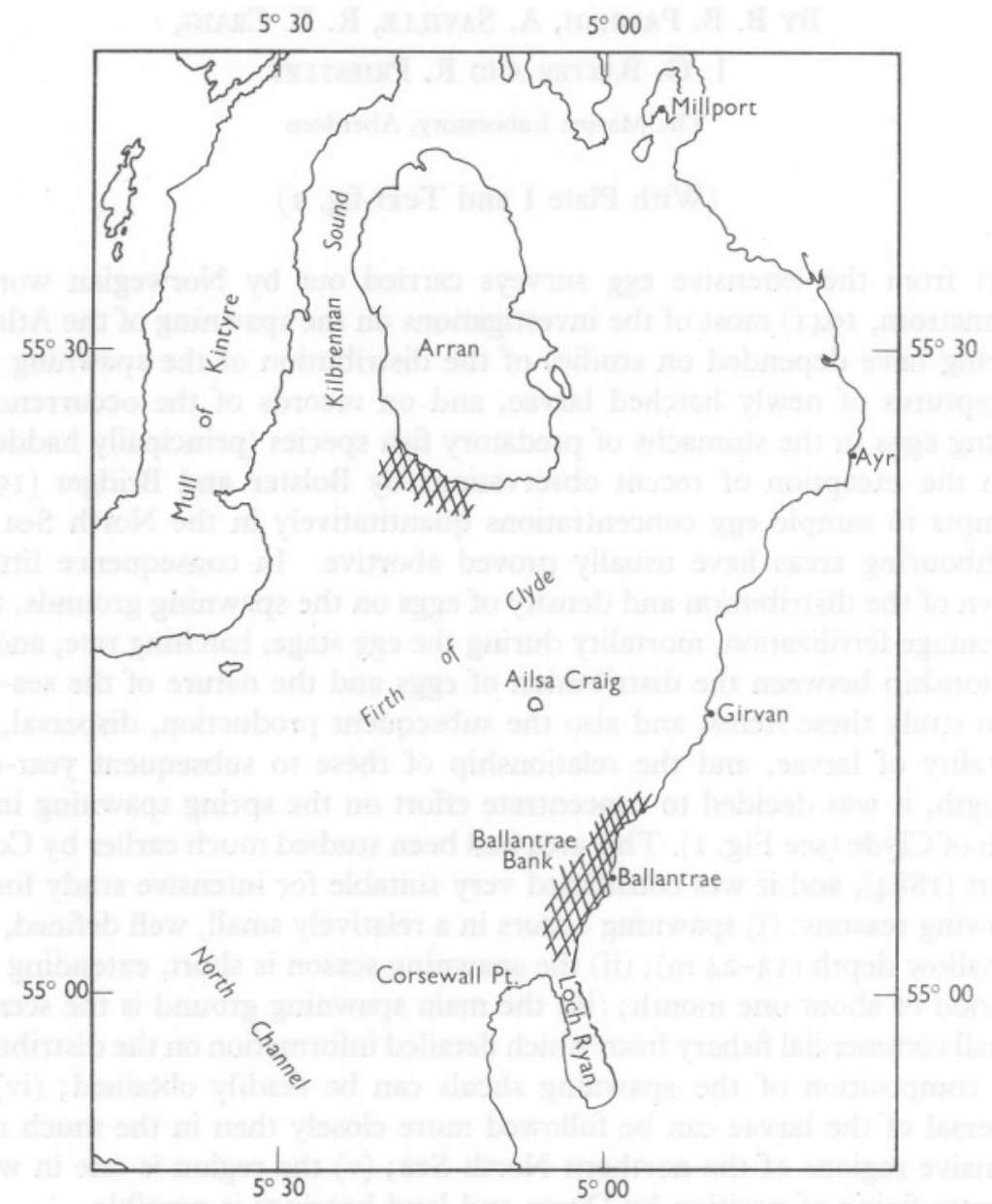

Fig. I. Chart of outer reaches of Firth of Clyde showing main spawning areas (hatched).

\section{SAMPLING OF EGG CONCENTRATIONS}

In 1957 and 1958, surveys of egg concentrations have been restricted to the larger of the two spawning grounds, Ballantrae Bank. Preliminary work in February and March 1957, and again in greater detail during the same period 
in 1958, consisted of an intensive survey by a continuous series of dredge hauls over the full extent of the bank. This provided a detailed picture of the nature of the sea-bed and the presence or absence of eggs. An egg patch was located in both 1957 and 1958, but only in 1958 was it possible to investigate the extent of the patch and the distribution and density of the eggs.

The procedure in 1958, after the egg patch had been located by dredge on 4 March, was to mark the position accurately by buoys and with Decca fixes, and then to sample the full extent of the patch with a small grab (mouth aperture $20 \times 20 \mathrm{~cm}$ ), designed for sampling in conjunction with the laboratory's underwater T.V. unit (shown in Pl. IA). By this means, and using the Decca track plotter, it was possible to delimit accurately the boundaries of the patch, to determine the distribution of the eggs and to estimate their total abundance and density. A series of underwater colour transparencies was also taken over the patch using the laboratory's $\mathrm{Mk} \mathrm{V}$ camera equipped with electronic flash. This proved very satisfactory as a survey instrument for this type of work, and black and white prints, taken from the colour transparencies, are shown in Pl. IB.

The most important results obtained from the dredge, grab and photographic surveys are as follows.

(I) The eggs sampled in both years were located in an area of small stones and gravel. No eggs were found in areas of large stones, boulders or rock.

(2) The egg patch surveyed in detail in 1958 was sharply delimited, the boundaries coinciding with a change in the substratum from gravel and small stones to large stones and rock. The patch was approximately square, measuring $320 \times 320 \mathrm{~m}$.

(3) Eggs were distributed in an almost continuous carpet, ranging from I-2 eggs thick at the boundaries to $4-8$ eggs thick over the greater part of the patch.

(4) Detailed examination of eggs taken from different parts of the patch indicated that no hatching had taken place up to the time of locating it. The stage of development varied markedly throughout the egg layer. The eggs in the surface layer were in an advanced stage of development near to hatching, while those in the lower layers were in earlier stages of development. These observations suggest that the eggs were all deposited at approximately the same time, and that the development of the eggs in the lower layers was retarded, due possibly to reduced oxygen supply.

(5) Very few unfertilized or dead eggs were observed in the samples taken from the patch, and there was no significant increase in the thickest layers of eggs. In the samples of eggs examined, the proportion of unfertilized or dead eggs did not exceed $\mathrm{I} \%$.

(6) No invertebrate fauna was observed over the whole extent of the egg patch, although dense concentrations of ophiuroids were sampled on a similar substratum in the vicinity of the patch and on other parts of the bank. 


\section{Abundance of eggs and numbers of spawners}

From a knowledge of the size of the egg patch, the distribution of eggs within it, the thickness of the egg layers, and the average egg diameter, it is possible to estimate the total number of eggs in the spawning patch. The number of spawning females and the total number of spawners producing the patch can then be calculated from data on the average fecundity and sex ratio.

Estimates of these quantities are given in Table $\mathrm{I}$. These estimates are based on there being a continuous carpet of eggs over the patch, and they are given for upper (5) and lower (2) levels of egg layer thickness, within which the actual average egg layer thickness certainly lay. (The average thickness of 50 samples of eggs taken over the patch was 4.) The fecundity value used was for fish of $26-27 \mathrm{~cm}$, which corresponded to the mode of the length composition of the catches taken by the commercial fishery on the bank, and the 50:50 sex ratio used does not differ significantly from that observed in the commercial samples.

TABLE 1. ESTIMATES OF EGGS IN PATCH AND NUMBER OF SPAWNING FISH

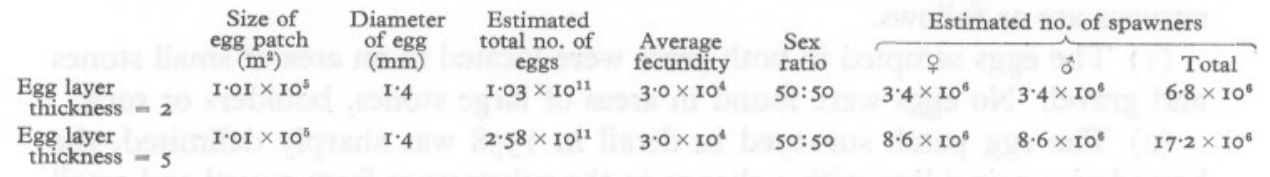

These calculations indicate that the total number of herring of both sexes contributing to the spawning patch lay between 7 million and 17 million fish. The estimates of average egg layer thickness obtained during the survey suggest that the actual number was nearer the upper of these two limits, and that Io million fish represents a reasonable conservative estimate.

That this spawning patch did not constitute the total spawning on Ballantrae Bank during the whole of the spawning season in 1958 is evident from other information. Ripe herring were caught by the commercial fishery on the bank after the time that the egg patch had been located; larval records obtained subsequent to the location of the egg patch indicated that substantial spawning took place after this time. Also running fish and a few spents were caught in the fishery on the bank at a time before the formation of the sampled egg patch. The general course of the fishery and the subsequent larval data indicate that the sampled patch was formed near the beginning of the spawning season, and that substantial spawning took place on the bank subsequently. From these data it is estimated that the total number of spawners on the bank during the spawning season was 4-5 times greater than the number contributing to the sampled egg patch. This gives rough limits for the total spawning stock size of between 30 million and 85 million fish. 


\section{Rate of exploitation}

A comparison of these estimates of the size of the spawning stock with the catches taken by the commercial fishery on the bank, during the spawning season, provides information on the rate of exploitation. This fishery is pursued with anchored gill nets during February and March. The anchored nets are shot in fleets of Io across the bank; they are set to fish throughout $24 \mathrm{~h}$, and are usually hauled in the morning. The positions of the nets are changed from time to time according to the regions on the bank at which the heaviest catches are being taken.

The statistics of this fishery in 1958, from its commencement at the beginning of February to its termination in late March, are given in Table 2.

$\begin{array}{ccc} & \text { TABLE } 2 & \\ \text { Week } & \begin{array}{c}\text { Total no. } \\ \text { net-days }\end{array} & \begin{array}{c}\text { Total catch } \\ \text { (crans) }\end{array} \\ \text { 3-8 February } & \text { I20 } & 39 \cdot 5 \\ \text { I0-I5 February } & 750 & \text { 185.0 } \\ \text { I7-22 February } & 750 & 207 \cdot 75 \\ \text { 24 February-I March } & 750 & 65 \cdot 5 \\ \text { 3-8 March } & 750 & 66 \cdot 5 \\ \text { I0-15 March } & 570 & 77 \cdot 5 \\ \text { I7-22 March } & 450 & 16 \cdot 25 \\ \text { Total } & 4140 & 658 \cdot 0\end{array}$

Estimates of the proportion of the total spawning stock taken by the fishery can be made from these catch data and the estimates of spawning stock size, both for the total spawning season and for the spawners contributing to the sampled egg patch. The number of herring per cran in this fishery averaged approximately 1000, which gives a total catch during the season of about 658000 herring. This constitutes a fraction of between

$$
\frac{0.658 \times 10^{6}}{85.0 \times 10^{6}}=0.8 \% \text { and } \frac{0.685 \times 10^{6}}{30.0 \times 10^{6}}=2.2 \%
$$

of the total number of spawners on the bank.

Similarly, estimates can be made of the herring contributing to the sampled spawning patch which were taken by the fishery. From the stage of development of the eggs in the patch it is estimated that they were fertilized I2-I3 days previously. This fixes the spawning date as on or about 22 February. The catch by the fishery up to this date amounted to 432 crans, and on the assumption that the herring available to the fishery up to this time all contributed to the sampled spawning patch, the estimate of the proportion taken by the fishery up to this time lies between

$$
\frac{0.432 \times 10^{6}}{17.2 \times 10^{6}}=2.5 \% \text { and } \frac{0.432 \times 10^{6}}{6.8 \times 10^{6}}=6.4 \%
$$


These estimates are in fact over-estimates, since it is known that in the early part of the season some spawning took place over parts of the bank other than the sampled patch. It is evident therefore that the seasonal fishing mortality rate of this spawning stock in 1958 was probably between $\mathrm{I}$ and $3 \%$.

\section{LARVAL ABUNDANCE AND DISTRIBUTION}

The larval surveys carried out in 1958 subsequent to the egg surveys were planned with the two primary objectives of assessing the numbers of eggs spawned over the season, and of tracing the subsequent dispersal of the larvae produced from them. The first of these aims demanded a close 'spawning' grid of stations covering the limited area on Ballantrae Bank within which spawning was known to take place, to be worked and repeated at frequent intervals; the second required a grid of more widely spaced stations over the Clyde estuary. The attempt to fulfil both of these requirements inevitably resulted in sampling falling rather short of the ideal in both cases.

The 'spawning' grid of sixteen stations was completed fifteen times between 2I February and 2I April. Sampling was by means of oblique hauls from bottom to surface with a one metre net of bolting silk with 60 threads to the inch.

Recently hatched larvae were found from 3 March to 9 April. Hatching was greatest, however, between IO and I4 March, with a distinct but very secondary mode around 7 April. Only negligible production of larvae occurred in the intervening period.

An indispensable preliminary to assessing the numbers of larvae produced was to estimate the rate at which larvae were removed from the bank. It was possible to estimate this from the rate at which the numbers on the bank fell off between I8 and 3I March, and again after 7 April, during which periods no, or only negligible, new production of larvae was taking place. In both of these periods the rate of loss from the bank was estimated to be about $75 \%$ per day. This loss is of course compounded of two factors, dispersion and mortality, but for this purpose it is not necessary to distinguish between them. This rate has been taken as applicable throughout the entire hatching period. Other assumptions made in estimating the number of larvae hatched were that the distribution was linear in space between stations, and in time between surveys. The former is not likely to lead to serious error in this case, where the stations were less than I mile apart. The latter is less reliable where, as happened on one occasion, surveys were separated by a period of 6 days, with a marked fall in larval numbers in the intervening period.

On this basis the number of larvae hatched on Ballantrae Bank during the $195^{8}$ spawning season was estimated at $5.4 \times 10^{11}$. This would be the progeny of about $2 \mathrm{I}_{2} \frac{1}{2}$ million spawning females if one assumes that all the eggs spawned 
subsequently hatched. (It has been shown in an earlier section that the proportion of dead or unfertilized eggs in the sampled patch was low, and no large concentrations of predators were encountered. It is likely, therefore, that mortality in the egg stage was low and that this assumption is reasonable.) This estimate is in broad agreement with that deduced from the estimation of the egg patch. It would suggest, as shown earlier, that there were perhaps four or five egg patches present on the bank during the course of the spawning season.

The larger grids, designed to follow the fate of the larvae subsequent to hatching, were completed eight times between ro March and 22 April. The first two surveys were carried out on IO and I2 March. On both of these larvae were sharply restricted to a narrow belt in the vicinity of Ballantrae Bank, and were evidently drifting southwards towards Loch Ryan and round Corsewall Point. Unfortunately there was then a gap of six days before the wide grid was resampled. During this period two marked changes had occurred. First, the numbers of larvae present in the survey area had fallen to less than $\mathrm{I} \%$ of their previous abundance; secondly, the sharp western boundary to the distribution of larvae had broken down and the few that remained were widely dispersed westwards to the limit of the survey area. That the marked reduction in abundance of these larvae was the result of drift westwards beyond the limits of the area surveyed, and probably out of the Clyde altogether, is supported by returns from drift bottles released over Ballantrae Bank during this period. The percentage return from these releases was very low, the few recovered being returned from the shores of Kintyre. The most plausible explanation of the low returns is that the remaining bottles were lost to the Atlantic.

The remnants of this group of larvae, which represented the preponderance of the season's production, only suffered a moderate mortality thereafter. By 3 April they were split into a smaller group in Kilbrennan Sound and a larger body off Corsewall Point and the mouth of Loch Ryan. These two groups retained their identity thereafter, the Kilbrennan Sound one being later found to the east of Arran, while that to the south showed a pulse-like movement, first moving south into the Irish Sea and then north again into the Clyde. This was also true of the larvae hatched during the second peak in early April, which showed distinct evidence of the same oscillation of the main body between the Clyde and the Irish Sea, with smaller bodies of larvae subsequently drifting northwards. These movements also are in substantial agreement with returns from later releases of drift bottles, which gave evidence of a southwards drift into the Irish Sea and subsequent return to the Clyde, with a predominantly northerly drift to the Ayrshire coast in the latter half of April.

Surveys of the sea lochs in the upper reaches of the firth were undertaken in late April and early May from M.V. 'Calanus', by kind permission of the 
Director of the Scottish Marine Biological Association Laboratory at Millport. They showed no evidence of larvae in these regions, in striking contrast to results in 1957, when large numbers of larvae were captured in these lochs at that time. The difference would seem to be due primarily to the different water movements in the two years. In 1958 there was a large loss of larvae from the Clyde due to predominantly westerly and southerly transport, while in 1957 the northerly drift tended to retain the larvae within the Clyde estuary. These water movements may be largely wind determined. In 1957 winds were predominantly southerly during the last three weeks of March, whilst in 1958 during this period the prevailing winds were from the east.

\section{SUMMARY}

In the period February-April 1958 an intensive survey was carried out on the herring spawning grounds of Ballantrae Bank, in the outer reaches of the Firth of Clyde, and over the regions of subsequent larval dispersal.

During a detailed dredge and grab survey of the bank an egg patch, measuring approximately $320 \times 320 \mathrm{~m}$ was located. This was confined to a gravel and small stone substratum. The eggs were distributed as an almost continuous carpet, with the layers of eggs ranging from two at the boundaries of the patch to eight in its densest parts. Very few dead or unfertilized eggs were observed, but the stage of development varied through the egg layer.

Estimates of the number of eggs in the patch lay between $\mathrm{I} .03$ and $2.58 \times \mathrm{IO}^{11}$ and of the number of spawners giving rise to them between 7 million and I7 million. These gave estimates for the total number of herring spawning on the bank during the season of between 30 million and 85 million.

Using these estimates of total spawning stock size, the seasonal fishing mortality rate was estimated to lie between I and $3 \%$.

Estimates of total spawning stock size obtained from data collected on subsequent quantitative larval surveys over the bank were in broad agreement with those derived from the egg survey. The dispersal of larvae from the bank was rapid and widespread, and a large proportion of the larvae were probably carried out of the Clyde estuary. The dispersion differed from that in 1957, when the bulk of the larvae were retained within the Firth of Clyde, and it corresponded with the dispersion of drift bottles, liberated on Ballantrae Bank during the hatching season.

\section{REFERENCES}

Bolster, G. C. \& BRIDGER, J. P., I957. Nature of the spawning area of herring. Nature, Lond., Vol. 179, 638.

Ewart, J. C., I884. Natural history of the herring. Rep. Fish. Bd. Scot., Vol. 2 (I883), pp. 6I-73.

Marshall, S. M., Nicholls, A. G. \& ORR, A. P., I937. Growth and feeding of the larval and post-larval stages of the Clyde herring. F. mar. biol. Ass. U.K., Vol. 22, pp. 245-67. 

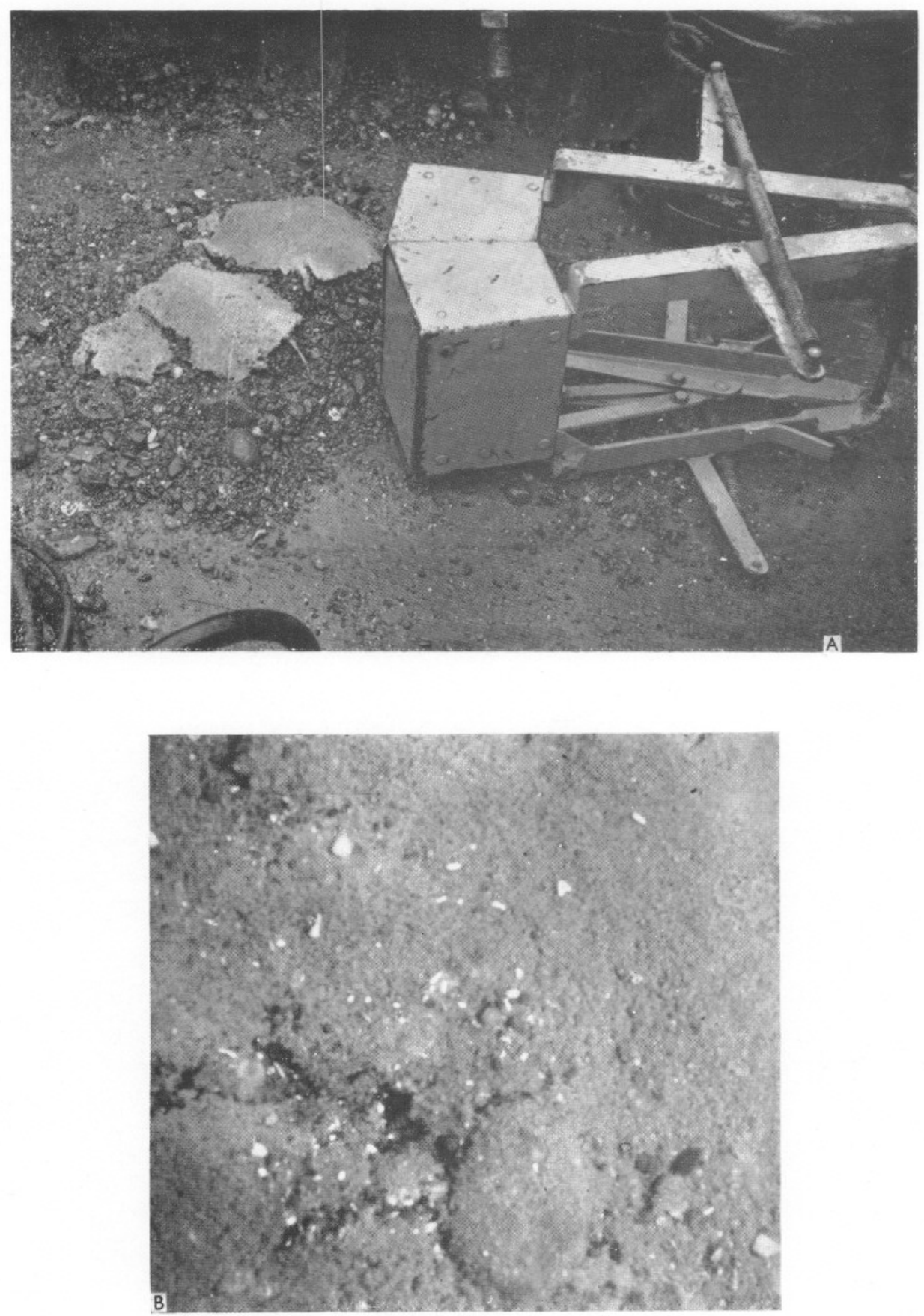

(Facing p. 453) 
Marshall, S. M., Nicholls, A. G. \& ORR, A. P., I939. 'On the growth and feeding of young herring in the Clyde.' F. mar. biol. Ass. U.K., Vol. 23, pp. 427-55.

RUNNSTROM, S., I94I. Quantitative investigations on herring spawning and its yearly fluctuations at the west coast of Norway. Fiskeridir. Skr. Havundersøk., Bd. 6, No. 8, 7I pp.

WooD, H., 1951. Observations on the value of $l_{1}$ in herring investigations. Rapp. Cons. Explor. Mer, Vol. I28, Pt I, pp. 39-46.

1958. Race characters of the herring of the Clyde Estuary. Summary. Rapp. Cons. Explor. Mer, Vol. I43, Pt 2, p. 65.

1959. (Paper in press).

\section{EXPLANATION OF PLATE I}

A. Grab used in egg survey, with egg sample taken in a single haul.

B. Print of eggs in situ taken with underwater camera. 